\title{
Glucose transporters in kidney; the role of gender and diabetes mellitus
}

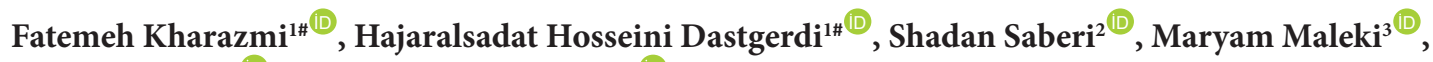 \\ Nepton Soltani ${ }^{1}{ }^{\circledR}$, Mehdi Nematbakhsh ${ }^{1,3,4^{*}}$ \\ ${ }^{1}$ Department of Physiology, Isfahan University of Medical Sciences, Isfahan, Iran \\ ${ }^{2}$ Physiology Research Center, Institute of Basic and Clinical Physiology Sciences, Kerman University of Medical Sciences, Kerman, Iran \\ ${ }^{3}$ Water and Electrolytes Research Center, Isfahan University of Medical Sciences, Isfahan, Iran \\ ${ }^{4}$ Isfahan ${ }^{\mathrm{MN}}$ Institute of Basic and Applied Sciences Research, Isfahan, Iran \\ "These two authors contributed equally to work.
}

\section{A R T I C L E I N F O}

\section{Article Type:}

Mini-Review

\section{Article History:}

Received: 7 April 2021

Accepted: 15 August 2021

ePublished: 1 October 2021

\begin{abstract}
A B S T RA C T
Sex hormones affect the developmental process and play important roles in the kidney's structure and functions. Clinical and experimental results have indicated that kidney functions are different between the genders, and they may be associated with the sex hormones, which regulate the expression and action of transporters in the nephron. In the current short review, the data banks including PubMed, Google Scholar, and Scopus were reviewed to achieve the published related articles regarding the role of gender and diabetes mellitus in glucose transport in renal system.
\end{abstract}

Keywords: Glucose, Kidney, Gender, Diabetes mellitus

\section{Implication for health policy/practice/research/medical education:}

It seems that the co-transporters of sodium-glucose (SGLTs) function is gender related, and to use SGLTs inhibitors as therapeutic agents in diabetic condition, the role of sex needs to be more specified.

Please cite this paper as: Kharazmi F, Hosseini Dastgerdi H, Saberi S, Maleki M, Soltani N, Nematbakhsh M. Glucose transporters in kidney; the role of gender and diabetes mellitus . J Nephropharmacol. 2022;11(1):e03. DOI: 10.34172/npj.2022.03.

\section{Introduction}

Facilitative D-glucose transport is mediated by members of the solute carrier transporter, glucose transporters (GLUTs), or uniporters family. Sodium-glucose cotransporters (SGLTs) involve in the D-glucose co-transport along with sodium, and its types 1and 2 (SGLT1 and SGLT2) are proteins that are encoded by the solute carrier family 5 member $1 \& 2$ (SLC5A1 and and SLC5A2) genes, respectively. SGLT2 (a high-capacity carrier) expresses in the S1 and S2 segments, while SGLT1 expresses in the S2 and S3 segments in human, rat and mice $(1,2)$. In normal condition, SGLT2 has the ability to reabsorb $95 \%$ or more of the filtered glucose, however, SGLT1 reabsorbs about $3 \%$ of the remained filtered glucose (3). Functional characteristics of SGLT2 and SGLT1 are coupling of $\mathrm{Na}^{+}$glucose coupling ratios (1:1 and 2:1), therefore this allows transporting the small amounts of glucose to the late proximal tubule.
The mediate actions of SGLT1 and SGLT2 are also different. Principally, the SGLT2 mediates the reabsorption of glucose, while SGLT1 is involved more in glucose reabsorption in the small intestine where SGLT2 is not expressed. The glucose that not reabsorbed in the early section of tubule could be reabsorbed in the late section of the tubule by SGLT1. $(1,3)$. Accordingly, glucose reabsorption by inhibition of SGLT1 in the kidney may perform a treatment process against the hyperglycemic condition, and on the other side, SGLT1 inhibitor alone or with SGLT2 as a therapeutic may use, for the treatment of hyperglycemia and diabetes mellitus.

Sex hormones, gender, and glucose transporters

A kind of dimorphism is involved in the glucose uptake regulation by sexual hormones. In the polycystic ovarian syndrome, GLUT expression and glucose metabolism are defected, and insulin resistance is occurred (4). 
Testosterone therapy in male and female animals decreases glucose transport by down-regulating of GLUT1 (5) while estradiol via receptor $\beta$ shows a causing or producing diabetes (diabetogenic) activity (6). In physiological concentration, both sexual hormones; testosterone and estradiol, preserve a normal insulin sensitivity (4). Testosterone also may increase insulin sensitivity in diabetes type 2- induced hypogonadism (7). The higher kidney SGLT1 (rSglt1) and SGLT2 (rSglt2) expressions have been found in female rats compared with male rats, while the higher expression of SGLT2 has been detected in the kidney of male mice $(2,8,9)$. The expression levels of SGLT1 and SGLT2 are reported to be sex-independent in human (10). It is reported that SGLT1 in the rat's kidney was a $75-\mathrm{kDa}$ protein expressed mainly in the S3 segments of proximal tubule, and its expression was androgen and sex dependent (9). It is also reported that the amount of SGLT2 protein was male dominant in the mouse kidneys, while the SGLT2 mRNA expression was female dominant, and in rodents the SGLT2 expression was kidney-specific (8). The GLUT carriers and SGLTs are encoded by solute carrier family 2 (SLC2) and SLC5 genes respectively, and the main substrates of facilitative GLUT carriers are glucose, galactose, mannose, glucosamine, and the main substrate of SGLTs is biotin, lipoate, and pantothenate that all are higher in female than male (11). The relating mRNAs of the renal GLUT1 and SGLT isoforms were expressed at greater levels in female compared with male mice while no considerable sex difference was detected in serum level of glucose (12). Madunić et al reported that expression of SGLT1 in male is more than female mice, but there is a female-dominant expression in rats (13). Moreover, it is clear that the expression of SGLT2 mRNA in female kidney was higher than male, but the SGLT2 protein expression was reversed, which reveals that the gender difference in renal SGLT2 protein is not explained by the expression of different levels of mRNA (8).

\section{Glucose transporters and diabetes}

In order to control the blood glucose in diabetic patients, it is necessary to reduce the development of metabolic abnormalities and decrease the risk of complications such as nephropathy and cardiovascular disorders. Accordingly, special attention has been made to SGLTs due to their ability to cure diabetes. The most attention has been paid to the SGLT2 subtype, which is responsible for more than $90 \%$ of renal glucose reabsorption, thereby SGLT2 inhibitors are candidates as oral anti-diabetics drugs. It is clear that diabetes itself increases the SGLT2 expression, and the maximum amount of transported glucose causes an additional increase in renal glucose reabsorption. The protective effect of SGLT2 inhibitors in diabetic patients and chronic kidney diseases was reported (14). However, the effect of SGLT2 inhibitors is also related to dietary approach in patients with type 2 diabetes (15).
Uncontrolled hyperglycemia can overcome the delivery capacity of early proximal SGLT2 so increasing the glucose transport to the late proximal tubule occurs, which enhances the glucose reabsorption by SGLT1. Experimental research on animal diabetic model demonstrates a rise of renal protein expression of SGLT2, which contributed to increase renal glucose reabsorption capacity (16). In the renal cortex of streptozotocininduced diabetic rats, an increase in mRNA expression for SGLT1 (17). Similarly, in diabetic obese Zucker rats, the level of renal SGLT1 mRNA was more than that of immature non-diabetic lean rats (18), and the smaller expression of SGLT1 mRNA but higher expression of renal membrane SGLT1 protein were detected in BTBR ob/ob T2DM mice (animal model of diabetic nephropathy) (19). The renal expression and activity of SGLT1 decreased in streptozotocin-induced diabetes (20). Additionally, the SGLT2 knockout mice showed a decreased expression of renal SGLT1 protein (21). Therefore, down-regulation in renal SGLT1 expression may limit glucose uptake and toxicity in the late proximal tubule when glucose load and reabsorption are enhanced $(1,21)$ while in normoglycemic mice, SGLT2 and SGLT1 are responsible for all renal glucose reabsorption (3). It is unclear whether this applies to the diabetic kidney or not.

It is showed that in the proximal tubule, GLUT2 translocation to the luminal brush border membrane is related to a rise in facilitative glucose reabsorption (22). The in-vitro research by Ghezzi and Wright, indicated that human SGLT2 was sensitive to insulin and its activity increased significantly by insulin, but human SGLT1 was moderately insensitive to insulin (23). In addition, the in-vitro experiments in proximal tubular cells of rabbits kidney showed that oxidative stress caused by high glucose could reduce the expression and activity of SGLT2 and SGLT1 (24). The inhibition of SGLT2 improves the control of blood glucose in diabetes while the glucose transport increases by SGLT1. However, the quantitative role of kidney SGLT1 in diabetes and kidney damage has not yet been exactly understood, and more studies are needed. Finally the role of sex on benefits of SGLT2 inhibitors in glucose controlling in diabetes is not clear yet, and needs to be specified.

\section{Conclusion}

Most findings have revealed a greater proportion of SGLT1 and SGLT2 in female rats compared with males. However in male mice greater SGLT2 existed compared with female mice. However, additional investigations have reported that in humans, these carriers are not affected by gender. In diabetes, SGLT1 expression is reduced in female and male mice and rats. SGLT1 expression in mice and rats reduces, which is to independent gender. To use SGLT inhibitors as therapeutic agents in diabetic condition, the role of sex needs to be more specified. 


\section{Authors' contribution}

FK, HHD, SS, MM, NS and MN were involved in preparing the literature review and preparing the draft. The final draft of the article was edited by $\mathrm{MN}$ and it was read by all authors. All authors signed the final manuscript.

\section{Conflicts of interest}

No conflict of interest was declared by the authors.

\section{Ethical issues}

Ethical issues (including plagiarism, data fabrication, double publication) have been completely observed by the authors.

\section{Funding/Support}

Nil.

\section{References}

1. Vallon V, Platt KA, Cunard R, Schroth J, Whaley J, Thomson SC et al. SGLT2 mediates glucose reabsorption in the early proximal tubule. J Am Soc Nephrol. 2011;22:104-12. doi: 10.1681/ASN.2010030246.

2. Balen D, Ljubojevic M, Breljak D, Brzica H, Zlender $\mathrm{V}$, Koepsell $\mathrm{H}$, et al. Revised immunolocalization of the $\mathrm{Na}+\mathrm{-D}$-glucose cotransporter SGLT1 in rat organs with an improved antibody. Am J Physiol Cell Physiol. 2008;295:C475-89. doi: 10.1152/ajpcell.00180.2008.

3. Rieg T, Masuda T, Gerasimova M, Mayoux E, Platt K, Powell DR, et al. Increase in SGLT1-mediated transport explains renal glucose reabsorption during genetic and pharmacological SGLT2 inhibition in euglycemia. Am J Physiol Renal Physiol. 2014;306:F188-93. doi: 10.1152/ ajprenal.00518.2013.

4. Livingstone C, Collison M. Sex steroids and insulin resistance. Clin Sci (Lond). 2002;102:151-66. doi: 10.1042/ cs1020151.

5. Nualart F, Los Angeles García M, Medina RA, Owen GI. Glucose transporters in sex steroid hormone related cancer. Curr Vasc Pharmacol. 2009;7:534-48. doi: 10.2174/157016109789043928.

6. Barros RP, Gabbi C, Morani A, Warner M, Gustafsson JA. Participation of ERalpha and ERbeta in glucose homeostasis in skeletal muscle and white adipose tissue. Am J Physiol Endocrinol Metab. 2009;297:E124-33. doi: 10.1152/ajpendo.00189.2009.

7. Dhindsa S, Ghanim H, Batra M, Kuhadiya ND, Abuaysheh $\mathrm{S}$, Sandhu S, et al. Insulin resistance and inflammation in hypogonadotropic hypogonadism and their reduction after testosterone replacement in men with type 2 diabetes. Diabetes Care. 2016;39:82-91. doi: 10.2337/dc15-1518.

8. Sabolic I, Vrhovac I, Eror DB, Gerasimova M, Rose M, Breljak D, et al. Expression of Na+-D-glucose cotransporter SGLT2 in rodents is kidney-specific and exhibits sex and species differences. Am J Physiol Cell Physiol. 2012;302(8):C1174-88. doi: 10.1152/ajpcell.00450.2011.

9. Sabolić I, Skarica M, Gorboulev V, Ljubojević M, Balen D, Herak-Kramberger CM, et al. Rat renal glucose transporter SGLT1 exhibits zonal distribution and androgendependent gender differences. Am J Physiol Renal Physiol.
2006;290:F913-26. doi: 10.1152/ajprenal.00270.2005.

10. Vrhovac I, Balen Eror D, Klessen D, Burger C, Breljak $\mathrm{D}$, Kraus $\mathrm{O}$, et al. Localizations of $\mathrm{Na}(+)$-D-glucose cotransporters SGLT1 and SGLT2 in human kidney and of SGLT1 in human small intestine, liver, lung, and heart. Pflugers Arch. 2015;467:1881-98. doi: 10.1007/s00424-0141619-7.

11. Sabolić I, Asif AR, Budach WE, Wanke C, Bahn A, Burckhardt G. Gender differences in kidney function. Pflugers Arch. 2007;455:397-429. doi: 10.1007/s00424-0070308-1.

12. Nagai K, Yoshida S, Konishi H. Gender differences in the gene expression profiles of glucose transporter GLUT class I and SGLT in mouse tissues. Pharmazie. 2014;69:856-9. doi: 10.1691/ph.2014.4647

13. Madunić IV, Breljak D, Karaica D, Koepsell H, Sabolić I. Expression profiling and immunolocalization of $\mathrm{Na}^{+}-\mathrm{D}$ glucose-cotransporter 1 in mice employing knockout mice as specificity control indicate novel locations and differences between mice and rats. Pflugers Arch. 2017;469:1545-65. doi: 10.1007/s00424-017-2056-1.

14. Miyoshi H, Kameda H, Yamashita K, Nakamura A, Kurihara Y. Protective effect of sodium-glucose cotransporter 2 inhibitors in patients with rapid renal function decline, stage G3 or G4 chronic kidney disease and type 2 diabetes. J Diabetes Investig. 2019;10:1510-7. doi: 10.1111/jdi.13064.

15. Nunoi K, Sato Y, Kaku K, Yoshida A, Suganami H. Renal effects of a sodium-glucose cotransporter 2 inhibitor, tofogliflozin, in relation to sodium intake and glycaemic status. Diabetes Obes Metab. 2019;21(7):1715-24. doi: 10.1111/dom.13731.

16. Vallon V. The mechanisms and therapeutic potential of SGLT2 inhibitors in diabetes mellitus. Annu Rev Med. 2015;66:255-70. doi: 10.1146/annurevmed-051013-110046.

17. Vestri S, Okamoto MM, de Freitas HS, Aparecida Dos Santos R, Nunes MT, Morimatsu M, et al. Changes in sodium or glucose filtration rate modulate expression of glucose transporters in renal proximal tubular cells of rat. J Membr Biol. 2001;182(2):105-12. doi: 10.1007/s00232-0010036-y.

18. Tabatabai NM, Sharma M, Blumenthal SS, Petering DH. Enhanced expressions of sodium-glucose cotransporters in the kidneys of diabetic Zucker rats. Diabetes Res Clin Pract. 2009;83:e27-30. doi: 10.1016/j.diabres.2008.11.003.

19. Gembardt F, Bartaun C, Jarzebska N, Mayoux E, Todorov VT, Hohenstein B, et al. The SGLT2 inhibitor empagliflozin ameliorates early features of diabetic nephropathy in BTBR ob/ob type 2 diabetic mice with and without hypertension. Am J Physiol Renal Physiol. 2014;307(3):F317-25. doi: 10.1152/ajprenal.00145.2014.

20. Albertoni Borghese MF, Majowicz MP, Ortiz MC, Passalacqua Mdel R, Sterin Speziale NB, Vidal NA. Expression and activity of SGLT2 in diabetes induced by streptozotocin: relationship with the lipid environment. Nephron Physiol. 2009;112:45-52. doi: 10.1159/000214214.

21. Vallon V, Gerasimova M, Rose MA, Masuda T, Satriano J, Mayoux E, et al. SGLT2 inhibitor empagliflozin reduces renal growth and albuminuria in proportion to hyperglycemia and prevents glomerular hyperfiltration in diabetic Akita 
mice. Am J Physiol Renal Physiol. 2014;306:F194-204. doi: 10.1152/ajprenal.00520.2013.

22. Marks J, Carvou NJ, Debnam ES, Srai SK, Unwin RJ. Diabetes increases facilitative glucose uptake and GLUT2 expression at the rat proximal tubule brush border membrane. J Physiol. 2003;553:137-45. doi: 10.1113/ jphysiol.2003.046268.

23. Ghezzi C, Wright EM. Regulation of the human Na+- dependent glucose cotransporter hSGLT2. Am J Physiol Cell Physiol. 2012;303(3):C348-54. doi: 10.1152/ ajpcell.00115.2012.

24. Han HJ, Lee YJ, Park SH, Lee JH, Taub M. High glucose-induced oxidative stress inhibits $\mathrm{Na}+$ /glucose cotransporter activity in renal proximal tubule cells. Am J Physiol Renal Physiol. 2005;288:F988-96. doi: 10.1152/ ajprenal.00327.2004.

Copyright $\odot 2022$ The Author(s); Published by Society of Diabetic Nephropathy Prevention. This is an open-access article distributed under the terms of the Creative Commons Attribution License (http://creativecommons.org/licenses/by/4.0), which permits unrestricted use, distribution, and reproduction in any medium, provided the original work is properly cited. 